\title{
Osteogénesis imperfecta: Diagnóstico y manejo de una enfermedad huérfana en un hospital regional peruano. A propósito de un caso
}

Osteogenesis imperfecta: Diagnosis and management of an orphan disease in a Peruvian regional hospital. A case report

Dercy Centeno-Leguía ${ }^{1,2, \text { a }}$, Ciro J. Atauje-Trillo ${ }^{1,3, b}$

\section{RESUMEN}

La osteogénesis imperfecta es una enfermedad rara de herencia autosómica dominante en la cual existen anomalías en la síntesis o degradación del colágeno que afecta al tejido conectivo ocasionando múltiples fracturas. Neonato femenino, a término 38 semanas, nacido por cesárea, procedente de Pichari, ingresó por cuadro de dificultad respiratoria instalada durante atención inmediata. Al examen físico se palpa crepitaciones en articulaciones. La paciente fue diagnosticada de osteogénesis imperfecta en base a los hallazgos clínicos y de imágenes, al carecer de evaluaciones genéticas.

PALABRAS CLAVE: Osteogénesis imperfecta, genética, recién nacido, Perú. (Fuente: DeCS BIREME).

\section{SUMMARY}

Osteogenesis imperfecta is a rare autosome dominant disease in which there are anomalies in the synthesis of collagen affecting the connective tissue leading to multiple fractures. We present the case of a 38-week newborn from Pichari born of a cesarean section who presented respiratory failure. The patient presented crackles on the joints and was diagnosed on clinical grounds of osteogenesis imperfecta.

KEYWORDS: Osteogenesis imperfecta, genetics, newborn, Peru. (Source: MeSH NLM).

Escuela Profesional de Medicina Humana, Universidad Nacional de San Cristóbal de Huamanga. Ayacucho, Perú.

2 Sociedad Científica Medico Estudiantil San Cristóbal. Ayacucho, Perú.

3 Hospital Regional de Ayacucho. Ayacucho, Perú.

a Estudiante de medicina.

b Médico Pediatra. 


\section{INTRODUCCIÓN}

La Osteogénesis imperfecta (OI) llamada también como enfermedad de los huesos de cristal o huesos frágiles es una enfermedad monogénica, resultado de una mutación en los genes que dirigen la síntesis y función del colágeno tipo I, a nivel de sus dos dímeros: COL1A1 y COL1A2; y en menor frecuencia producto de una incorrecta alineación del triplete dextro-girado de glicina-prolina-hidroxiprolina ${ }^{(1)}$. Además, existen otros tipos de osteogénesis imperfecta causados por mutaciones en genes no asociados a colágeno. Estos genes, unos 17 aproximadamente, son chaperonas o tienen participación indirecta en la formación de la cadena de colágeno ${ }^{(2,3)}$. Recientemente mediante secuenciación clínica del exoma se han encontrado variantes en los genes COL1A1 Y COL1A2 por sustitución de glicina, también 2 variantes heterocigotas en el gen FKBP10 ${ }^{(4)}$.

Entre la variedad de manifestaciones clínicas de la osteogénesis imperfecta predominan las de tipo osteoarticular, fragilidad esquelética, múltiples fracturas a mínimos esfuerzos, fracturas producidas en el período fetal en las OI tipo II, pérdida de la audición, dentinogénesis imperfecta, escleróticas color gris azulado, talla baja, complicaciones neurológicas, respiratorias y cardiovasculares; a largo plazo artritis, escoliosis, talla baja. Coexiste también con macrocefalia, invaginación basilar e hidrocefalia $(1,5,6,7)$.

El diagnóstico clínico se realiza ubicando múltiples fracturas con distintos grados de consolidación, ligamentos laxos, huesos wormianos, vertebras "codfish", osteopenia u osteoporosis. El diagnóstico genético se basa en la secuenciación de los genes COL1A1 Y COL1A2 buscando las mutaciones autosómicas dominantes propias de la osteogénesis imperfecta ${ }^{(5,8)}$. De salir normales estos dos genes principales se procede a secuenciar los otros 17 genes relacionados a diferentes fenotipos de osteogénesis imperfecta ${ }^{(3)}$.

El tratamiento médico se basa en la administración de bifosfonatos, ácido zoledrónico, calcio, vitamina D ${ }^{(3,9)}$ como tratamiento quirúrgico se emplean reducciones abiertas y cerradas, y colocación de barras telescópicas intramedulares ${ }^{(2,4,10)}$.

La osteogénesis imperfecta es una enfermedad huérfana debido a su baja prevalencia. Para catalogar una enfermedad como huérfana debe registrar una prevalencia de 5 o menos casos por cada 10 000 habitantes (11). En Perú durante tres años de seguimiento se llegaron a reportan solo 11 pacientes en un hospital nacional ${ }^{(12)}$ y casos aislados en Piura ${ }^{(15)}$, Trujillo ${ }^{(7)}$ y Ucayali ${ }^{(13)}$. Los hospitales nacionales son los centros de mayor complejidad en el país, de los 15 hospitales nacionales que tiene el Perú, solo cinco se encuentran en las 23 regiones restantes, quienes en su mayoría poseen solo un hospital regional como sede de mayor complejidad, los cuales al no contar con todo el equipamiento refieren casos clínicos complejos o poco comunes a hospitales nacionales perdiéndose de la data del hospital regional y si por limitaciones económicas no lograsen llegar a los hospitales nacionales también se perderían de su data perpetuando su estado de enfermedades huérfanas por su baja prevalencia registrada. Por ello enfatizamos en la importancia de reportar casos clínicos como el presentado a continuación.

\section{PRESENTACIÓN DEL CASO}

Niña nacida a término (38 semanas de gestación), de parto abdominal por presentación podálica. El peso al nacer fue $2700 \mathrm{~kg}$, talla $41 \mathrm{~cm}$, perímetro cefálico $34 \mathrm{~cm}$, perímetro torácico de $32 \mathrm{~cm}$, APGAR 8 puntos al minuto y 9 puntos a los 5 minutos; se administró vitamina $\mathrm{K}$. La ecografía prenatal solo mostró anormalidades óseas en hueso fémur (figura 1). Luego del nacimiento presentó síndrome de distress respiratorio moderado (puntaje de 6 en escala de Silverman y Anderson). Al examen físico se encontró, fontanela posterior amplia con hipoplasia de hueso occipital, escleróticas de color azul (figura 2), milia en la nariz, cuello corto con piel redundante, crujido en región clavicular, extremidades inferiores de corta longitud, crepitación en parrilla costal, que producía dolor a la presión (figura 3).

La paciente no presentaba reflejo de deglución por lo que fue alimentada a través de sonda orogástrica; mientras estuvo hospitalizada desarrolló síndrome obstructivo bronquial agudo, conjuntivitis aguda y permaneció dependiente de oxígeno hasta el egreso.

Los padres procedían del distrito de Pichari, provincia de la Convención, departamento de Cusco, Perú; la madre de 33 años se dedica a actividades domésticas y el padre de 34 trabaja cultivando hoja de coca en contacto con productos químicos. La madre refirió haber sido diagnosticada de hipercolesterolemia y tener una hermana con diabetes mellitus tipo 2. No había antecedente familiar de personas con cuadro 


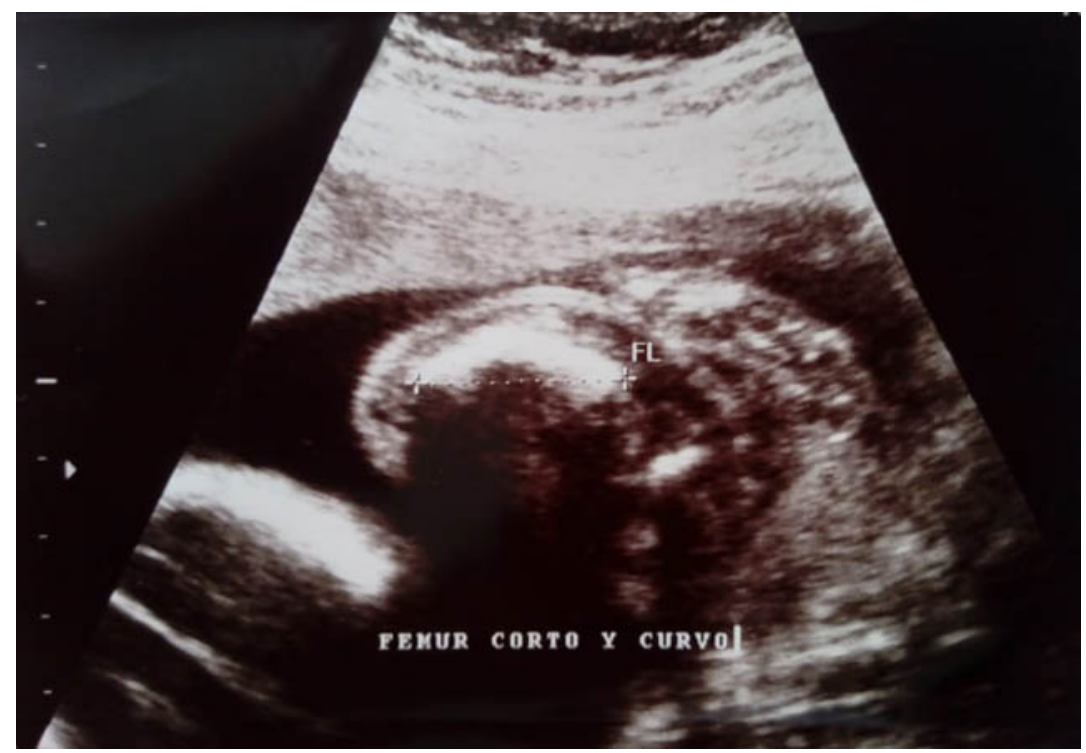

Figura 1. Ecografía prenatal: En la ecografía biométrica fetal se visualiza hueso fémur corto y curvo.

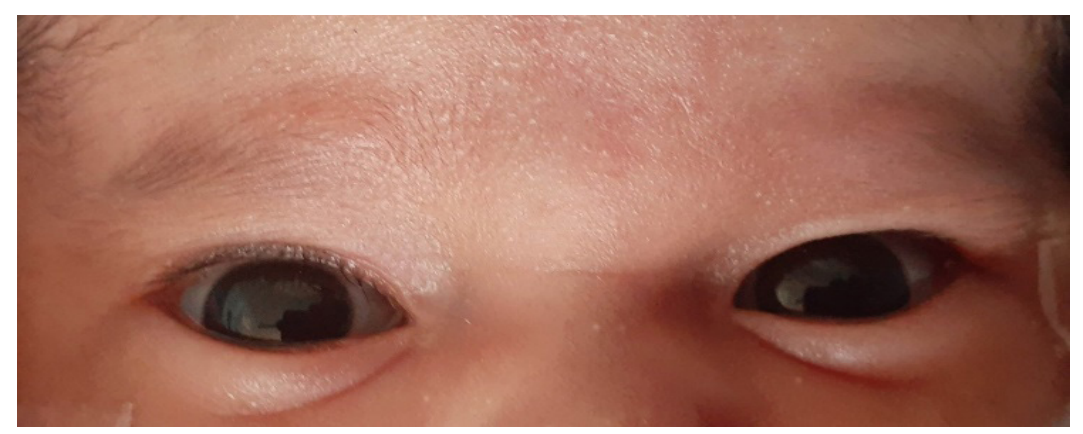

Figura 2. Fotografía del primer mes de vida, que muestra escleróticas de color azulado.

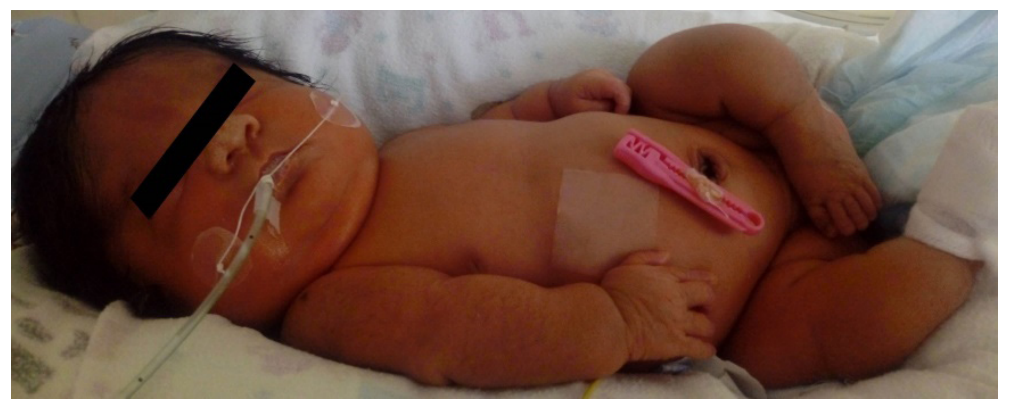

Figura 3. Primera semana de vida, se observa deformidades y micromelia en todas las extremidades.

clínico similar al de la recién nacida en la línea materna ni paterna, ni otro antecedente patológico de importancia en las tres gestaciones previas que terminaron por parto vaginal.

La madre tuvo adecuados controles prenatales durante la gestación, 7 en total. En la ecografía prenatal se evidenciaron malformaciones óseas en miembros inferiores, como fémur corto y curvo (figura 1), además de fracturas consolidadas.

Se planteó como diagnóstico Osteogénesis Imperfecta tipo II debido a las múltiples fracturas, en su mayoría intrauterinas, escleróticas color azul, dificultad respiratoria, además de las imágenes ecográficas y radiográficas. 


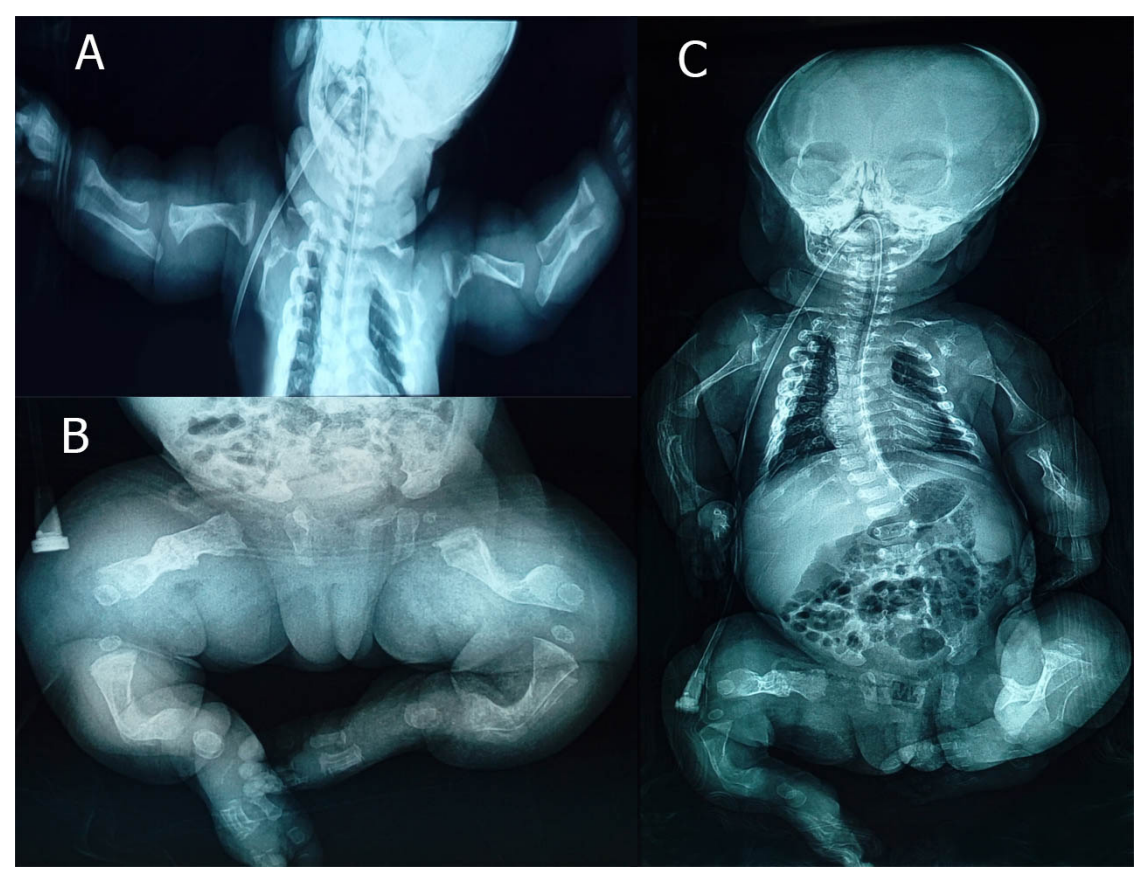

Figura 4. A. Radiografía de miembros superiores, fractura diafisiaria de húmero izquierdo, deformidades angulares. B. Radiografía de miembros inferiores, extremidades con deformidades angulares, tibias en antecurvatum. C. Radiografía completa anteroposterior expone marcada escoliosis, numerosas fracturas en distintos grados de consolidación, presencia de rosario costal deformidades angulares de huesos largos y un índice cardiaco aumentado.

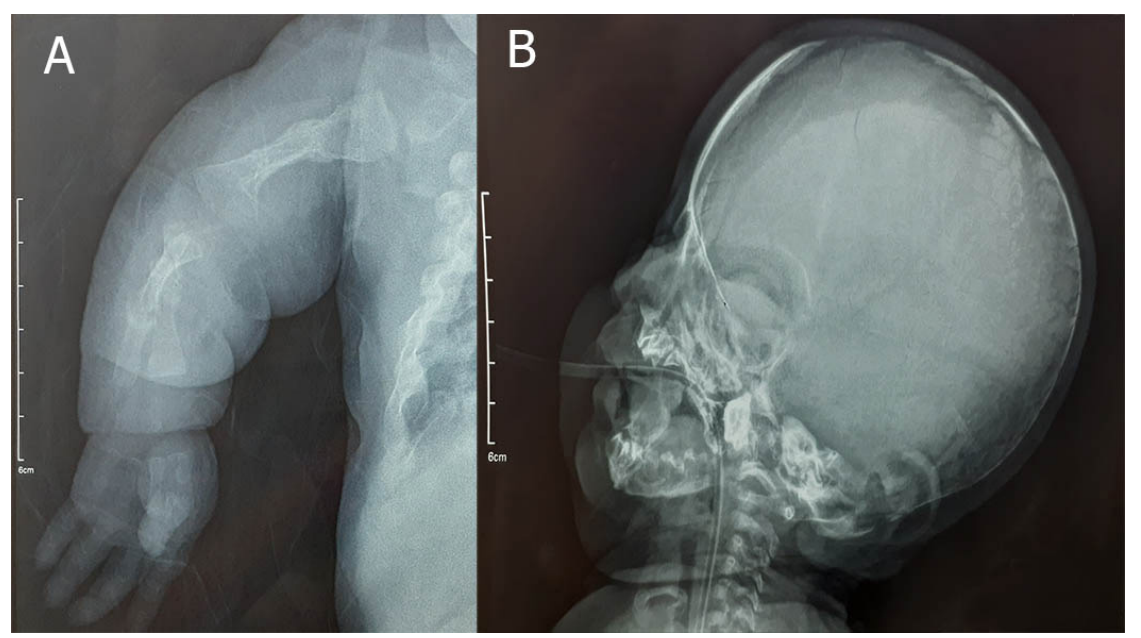

Figura 5. A. Radiografía postero-anterior de miembro superior izquierdo, micromelia, fractura consolidada de diáfisis de húmero, y deformidades angulares producto de fracturas, se evidencia fractura de húmero izquierdo consolidada, y fractura reciente de diáfisis cubital. B. Radiografía lateral de cráneo, en la cual se evidencia hipoplasia del hueso occipital.

\section{DISCUSIÓN}

La osteogénesis imperfecta es una enfermedad poco frecuente se estima una prevalencia mundial de 1/15 000 y 1/20 000, en España se estima una tasa de 0,29 por cada 10000 habitantes ${ }^{(7,8)}$. Cursa con un amplio espectro de manifestaciones clínicas que según la gravedad de los síntomas que produzca puede ser clasificada en diferentes tipos, siendo la tipo II la de peor pronóstico. Tradicionalmente la Osteogénesis imperfecta se clasifica bajo el sistema diseñado por Sillence en cuatro tipos (tabla 1$)^{(3,14,15)}$. 
Tabla 1. Clasificación de la osteogénesis imperfecta bajo el sistema diseñado por Sillence.

\begin{tabular}{ll}
\hline \multicolumn{1}{c}{ Tipo } & \multicolumn{1}{c}{ Características } \\
\hline I & Forma más leve, fractura comunes en el período neonatal, llegan a la edad adulta \\
II & Forma más grave, causa muerte al nacer o poco después de nacer \\
III & Tipo más grave en los niños, causa pérdida de la audición y deformidad ósea. Son raras las escleróticas azules \\
IV & Presenta deformidad ósea leve a moderada. Son raras las escleróticas azules \\
\hline
\end{tabular}

Los diagnósticos diferenciales son otras enfermedades que alteren la estructura armónica osteoarticular tales como lesiones traumáticas, raquitismo, displasia de miembros inferiores, displasia tanatofórica, displasia campomelítica, acondrogénesis tipo I, osteoporosis idiopática juvenil, hipofosfatemia congénita y osteomalacia ${ }^{(7,16)}$.

E1 25,2\% de los pacientes afectados por osteogénesis imperfecta tienen antecedentes familiares, en el caso descrito, los padres negaron casos similares en sus respectivas líneas familiares ${ }^{(5)}$.

El tratamiento médico se fundamenta en inicio precoz con bifosfonatos que incrementa la densidad del hueso y reduce el número de fracturas ${ }^{(3)}$. Hay estudios que plantean utilizar el ácido zoledrónico, sobre todo en niños con osteoporosis y osteogénesis imperfecta ${ }^{(9)}$. Dentro del manejo quirúrgico se destaca la técnica de Fassier-Duval Rod en la cual se insertan barras telescópicas intramedulares para corregir deformidades en huesos largos permitiendo su crecimiento y por su flexibilidad previenen nuevas fracturas en comparación a métodos anteriores que usaban dispositivos estáticos ${ }^{(2,4,10)}$.

Dentro del manejo se debe incluir un soporte emocional a los padres de familia dadas por personal calificado para tal fin, por tratarse de pacientes con un alto grado de dependencia y en muchos casos bajas probabilidades de supervivencia. La supervivencia de estos pacientes depende en gran medida de los cuidados brindados por los padres ${ }^{(6)}$. La complicación que se asocia con mayor mortalidad es la falla respiratoria en $33 \%{ }^{(5)}$.

El diagnóstico precoz de esta patología permite plantear un adecuado plan de parto así como un manejo del recién nacido con los cuidados necesarios, movilización mínima, lo que aumenta las posibilidades de supervivencia. Se requiere de mayores estudios sobre el tema y el apoyo de centros especializados para realizar diagnósticos precisos con tratamiento específico.
El diagnóstico en regiones alejadas del país es netamente clínico, debido a la carencia de exámenes genéticos y escasos recursos económicos de la familia para poder trasladarse a centros especializados; dichos factores son causantes de abandono de tratamiento. Si bien el diagnóstico definitivo es mediante secuenciación genética; reportes de caso con diagnósticos clínicos y radiográficos de Osteogénesis imperfecta contribuyen a la data nacional y permiten que el hospital tenga un registro de la casuística presente, reemergente y emergente con mayor posibilidad de poder derivar a estos pacientes a los centros especializados para un estudio a profundidad (figura 4 y figura 5).

\section{Conflictos de intereses:}

Los autores declaran no tener conflictos de interés

\section{Contribuciones de autoría:}

DCL y CAT participaron en la recolección de información, reacción del reporte y aprobación de la versión final del manuscrito.

\section{Correspondencia:}

Dercy Centeno-Leguía

Dirección: Av Maravillas $\quad N^{\circ} 296$. Huamanga, Ayacucho, Perú.

Correo electrónico: dercycenteno@gmail.com

Teléfono: 988202752

\section{REFERENCIAS BIBLIOGRÁFICAS}

1. Moreta H, Revelo E, Borja P, Vela M. Osteogénesis Imperfecta RECIMUNDO. 2019; 3(2):915-933.

2. Steiner RD, Basel D. COL1A1/2 Osteogenesis Imperfecta. En: GeneReviews. Seattle: University of Washington; 2020. (Citado el 15 de febrero del 2021) Disponible en: https://www.ncbi.nlm.nih.gov/ books/NBK1295/

3. Palomo T, Vilaça T, Lazaretti-Castro M. Osteogenesis imperfecta: diagnosis and treatment. Curr Opin Endocrinol Diabetes Obes. 2017; 24(6):381-388. 
4. Madhuri V, Selina A, Loganathan L, et al. Osteogenesis imperfecta: novel genetic variants and clinical observations from a clinical exome study of 54 Indian patients. Ann Hum Genet. 2020; 1:1-10.

5. Gimeno-Martos S, Pérez-Riera C, GuardiolaVilarroig S, Cavero-Carbonell C. Epidemiología de la Osteogénesis imperfecta: una enfermedad rara en la comunitat Valenciana. Rev Esp Salud Pública. 2017; 91: e201711045.

6. Sarmiento JC, Rojas JC, Wandurraga EA, Parra GA, Sarmiento JC. Osteogénesis imperfecta (OI) en una mujer adulta y su hija: reporte de caso. Revista ACE. 2016; 3(3):37-40

7. Concepción M, Cortegana J, Aguilar D, Zavaleta F. Osteogénesis imperfecta. Reporte de un caso. Rev Perú pediatr. 2014; 67 (4): 223-226.

8. Guaglione A, Sanchez M, Martinez J. Osteogénesis imperfecta tipo II: Reporte de un caso con una supervivencia mayor a cuatro meses Rev Mex Ortop Ped. 2013; 15(2):111-117.

9. Sánchez-Sánchez LM, Cabrera-Pedroza AU, Palacios-Saucedo G, Fuente-Cortez B. Zoledronic acid (zoledronate) in children with osteogénesis imperfecta. Gac Med Mex. 2015; 151:164-8.

10. Hidalgo S, Verde D. Osteogénesis imperfecta: tratamiento y manejo quirúrgico, Opinión actual en pediatría. 2021; 33(1):74-78.
11. Fujita R, Lizaraso F. Enfermedades Raras o Huérfanas, en Perú más huérfanas que raras. Horiz Med. 2018; 18(1):4-5.

12. Condori E R. Osteogénesis imperfecta en niños tratados en el Hospital Nacional Daniel Alcides Carrión entre los años 2007 y 2009: Callao, LimaPerú. Tesis de Grado. Lima, Perú: Universidad Nacional Mayor de San Marcos; 2011. 132 pp.

13. Velásquez Hurtado JE, Kusunoki Fuero L, Paredes Quiliche TG, Hurtado La Rosa R, Rosas AM, Vigo WE. Mortalidad neonatal, análisis de registros de vigilancia e historias clínicas neonatales del año 2011 en Huánuco y Ucayali. Perú. Rev Peru Med Exp Salud Publica. 2014; 31(2):228-36.

14. Sillence D. Osteogenesis imperfecta: an expanding panorama of variants. Clin Orthop Relat Res. 1981; 159:11-25.

15. Chetty M, Roomaney IA, Beighton P. The Evolution of the Nosology of Osteogenesis Imperfecta. Clinical Genetics. 2021; 99 (1):42-52.

16. Chávez N, Correa F. Osteogénesis imperfecta tipo III: reporte de un caso. Rev Arg Reumatol. 2013; 24(1): $50-53$.

Recibido: $15 / 08 / 2019$ Aceptado: 31/01/2020 